\title{
Environmental rearing conditions produce forebrain differences in wild Chinook salmon Oncorhynchus tshawytscha
}

\author{
R.L. Kihslinger , S.C. Lema, G.A. Nevitt
}

\begin{abstract}
Recent studies suggest that hatchery-reared fish can have smaller brain-to-body size ratios than wild fish. It is unclear, however, whether these differences are due to artificial selection or instead reflect differences in rearing environment during development. Here we explore how rearing conditions influence the development of two forebrain structures, the olfactory bulb and the telencephalon, in juvenile Chinook salmon (Oncorhynchus tshawytscha) spawned from wild-caught adults. First, we compared the sizes of the olfactory bulb and telencephalon between salmon reared in a wild stream vs. a conventional hatchery. We next compared the sizes of forebrain structures between fish reared in an enriched NATURES hatchery and fish reared in a conventional hatchery. All fish were size-matched and from the same genetic cohort. We found that olfactory bulb and telencephalon volumes relative to body size were significantly larger in wild fish compared to hatchery-reared fish. However, we found no differences between fish reared in enriched and conventional hatchery treatments. Our results suggest that significant differences in the volume of the olfactory bulb and telencephalon between hatchery and wild-reared fish can occur within a single generation.
\end{abstract}

Keywords: Enrichment; Fish; Hatchery; Neurogenesis; Phenotypic plasticity; Conservation; Salmon; Brain

\section{Introduction}

Variation in gross neuroanatomy often reflects the ecology and behavior of animals (birds: Healy and Guilford, 1990; cyprinid fish: Brandstatter and Kotrschal, 1990; Kotrschal and Palzenberger, 1992; cichlid fish: Huber et al., 1997). For example, among closely related species of cichlid fishes, the size of the olfactory bulb is larger in piscivores than in insectivores and zooplanktivores, while the size of the telencephalon is larger in shallow-water than in deep-water species (Huber et al., 1997). Variation in neural phenotype is thus often assumed to result from selection processes driven by ecologically divergent environments (Huber et al., 1997; Kotrschal et al., 1998). It has become increasingly clear, however, that environmental conditions experienced proximately during development also influence neural proliferation and phenotype across a variety of taxa. In mice, adults exposed to enriched environments show increased neural proliferation in the dentate gyrus of the hippocampus (Kempermann and Gage, 1999; van Praag et al., 2000); cortical depth and weight also increase (Rosenweig and Bennett, 1996). In fish, the size of neuroendocrine cells in the brain can be influenced by immediate environmental conditions such as social status and habitat stability (Semsar and Godwin, 2003; Lema and Nevitt, 2004a; Lema, 2006). While animals reared in captive or laboratory environments often exhibit neural phenotypes that differ from their wild counterparts (Plogmann and Kruska, 1990; Kruska, 1996), little attention has been directed towards understanding how captive environments proximately influence the development of the brain.

Salmon and trout provide an excellent model system to study environmental effects on brain growth, both because hatchery environments differ from natural habitats (Fig. 1), and because behavior and brain size can vary among hatchery-reared and wild-reared fish. In the wild, salmon spend the first portion of their life in dynamic fresh water streams. Eggs are laid in gravel nests (redds) and hatch into alevins. Alevins remain buried for a period of days to weeks before emerging to become freeswimming fish. In the hatchery, however, fish are reared in high densities in homogeneous concrete raceways with little environmental variability and are scatter-fed an artificial diet 


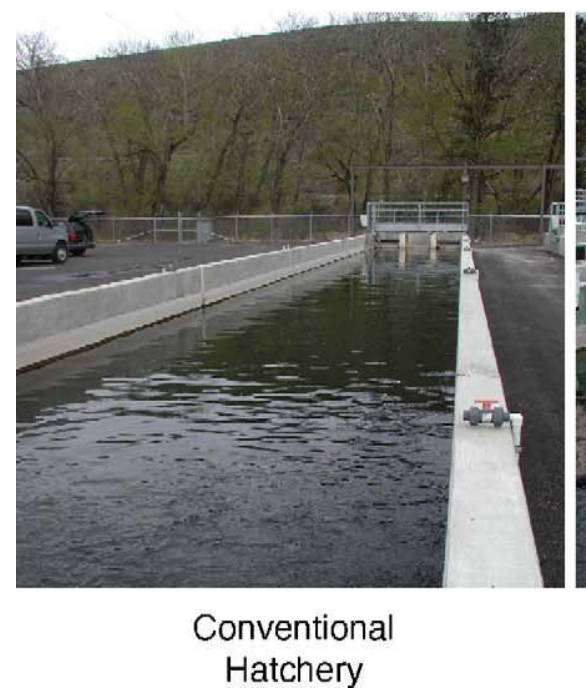

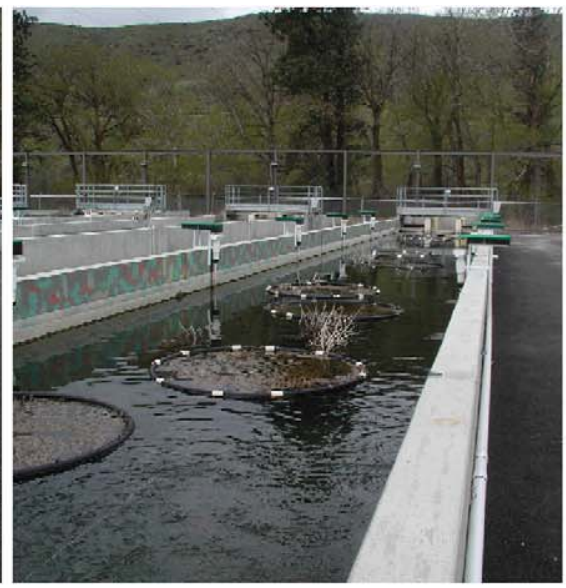

Enriched NATURES Hatchery

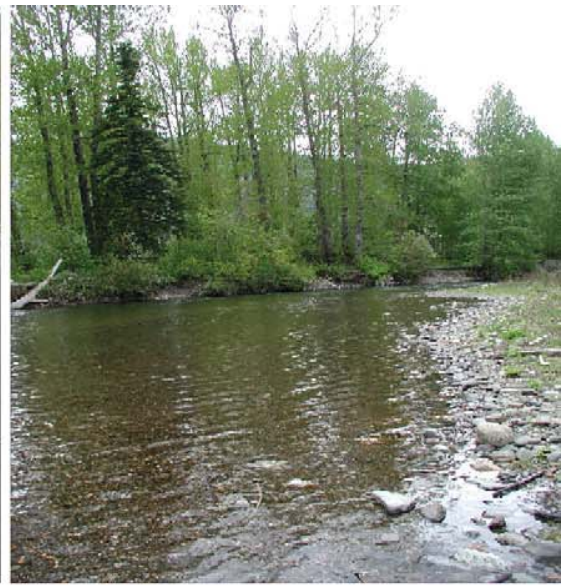

Yakima River

Fig. 1. Illustration of the conventional hatchery raceways, NATURES enriched hatchery raceways, and wild Yakima River environments.

from the surface. In either case, after about a year, depending on the species, juvenile salmon (parr) go through the parr-smolt transformation (i.e. smoltification), the transitional period when salmon undergo morphological, physiological, and behavioral changes that prepare them for migration into seawater.

Given these differences in rearing conditions, it is not surprising that hatchery fish show morphological and behavioral differences compared to their wild counterparts. For example, salmon and trout propagated in hatcheries often manifest growth and maturation patterns, and anti-predator, feeding, and sexual behaviors that differ dramatically from wild fish (Gross, 1998; Flagg et al., 2000). We have also recently shown that hatcheryreared rainbow trout (Oncorhynchus mykiss) have smaller forebrain structures (olfactory bulbs and telencephalons) relative to body size than wild fish (Marchetti and Nevitt, 2003). Marchetti and Nevitt's study compared brain morphology from a total of 99 fish sampled from two strains of hatchery fish and two geographically distinct populations of wild fish. When normalized to body size, hatchery-reared rainbow trout (Oncorhynchus mykiss) had significantly reduced olfactory bulbs, telencephalons, and optic tectums relative to trout reared in the wild. It is not known, however, to what extent these differences were due to a proximate, developmental response to the rearing environment or to artificial selection over generations.

Conservation hatcheries have been developed to produce fish with more wild-type qualities as well as to improve the low survival rates often observed when hatchery-reared fish are released into the wild. These hatcheries provide a convenient opportunity to investigate whether different rearing strategies impact brain growth because comparisons can be made among genetically similar fish reared in different environments. Conservation hatchery environments consist of conventional hatchery raceways enriched with some or all of the following features: automated underwater feeders, benthic substrate, instream structure, surface cover, live food diets, increased current velocities, or predator avoidance training (Maynard et al., 2003). These enrichment strategies have been shown to influence behavior and survival (Berejikian et al., 2000; Maynard et al.,
2003), but effects of such enriched environments on brain development in salmon are unknown.

In this study, we examined the size of two forebrain structures, the olfactory bulb (OB) and telencephalon (TE), in wild-reared, conventional hatchery-reared, and enriched hatchery-reared juvenile spring Chinook salmon (O. tshawytscha). All fish used in this study were offspring of one geneticallysimilar run of wild fish from the Yakima River. Wild-reared fish were never exposed to the hatchery environment. These fish were spawned by their parents in the wild, and developed in wild streams until the time of collection. By contrast, hatcheryreared fish were artificially spawned in the hatchery, and held in a common facility. They were transferred to different rearing environments (conventional, enriched) when they were approximately two months old. At about 1 year of age, these fish left the hatchery volitionally when they were ready to migrate.

We made two comparisons to assess the effect of rearing environment on brain growth. First, we compared olfactory bulb and telencephalon volumes between fish reared in wild and conventional hatchery environments. These fish were sampled during their down-stream migration. Second, we compared the size of these forebrain structures in juvenile salmon reared in conventional and enriched hatchery environments (Fig. 1). These fish were collected directly from their hatchery-rearing raceways and had not yet begun their downstream migration. Consequently, the goal of this study was twofold: 1) to explore how the growth of forebrain structures in genetically similar fish is influenced by two drastically different rearing environments, and 2) to examine whether one example of an enriched hatchery environment can mimic the effects of natural rearing on neural development.

\section{Materials and methods}

\subsection{Rearing}

Juvenile chinook salmon (Oncorhynchus tshawytscha) examined in this study were offspring of wild adults that returned to the Yakima River (Washington, USA) in the fall of 1999. 

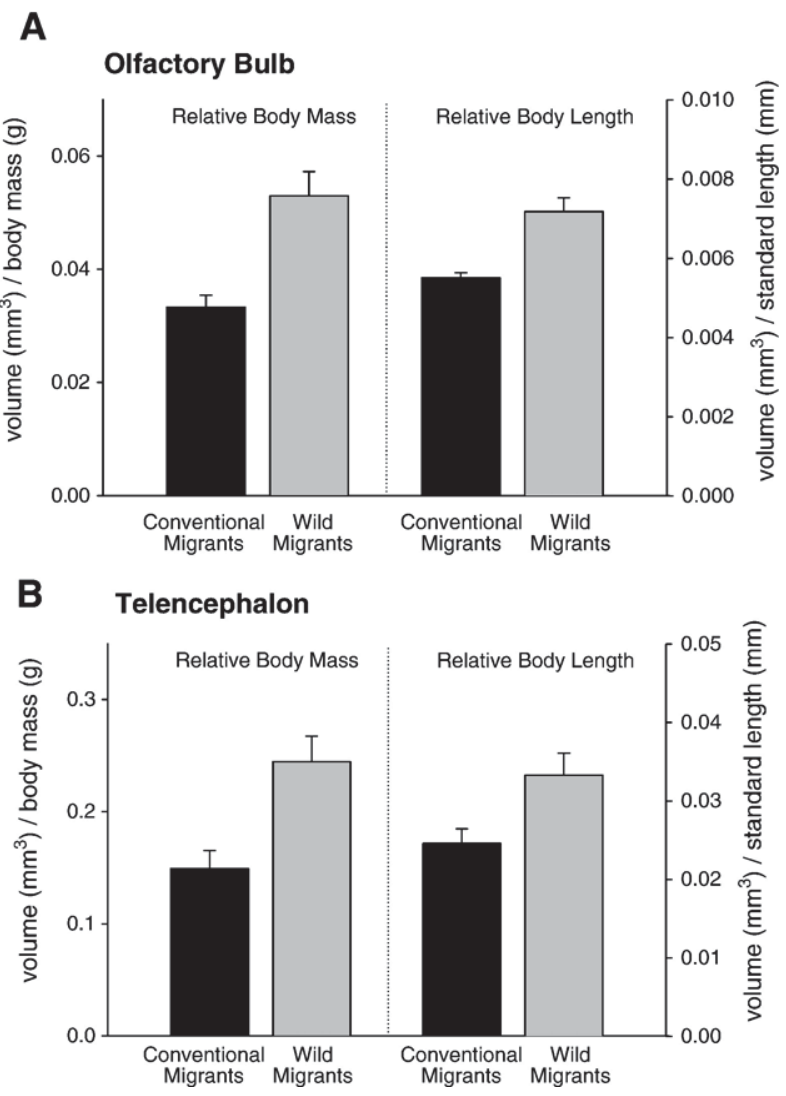

Fig. 2. Relative volume of the olfactory bulb (A) and telencephalon (B) shown normalized to body mass and standard length for migrating salmon reared in the wild and in conventional hatchery raceways. Values are plotted as mean $\pm \mathrm{SEM}$.

Wild-reared smolts were offspring of wild adults that spawned naturally in the Yakima River. For hatchery treatments, wild adults were collected at Roza Dam and spawned artificially in Cle Elum Hatchery. Eggs were incubated in Heath Trays until April 2000, when fish were ponded into conventional or enriched raceways $(30 \mathrm{~m} \times 3 \mathrm{~m} \times 1 \mathrm{~m}$; water flow $2200 \mathrm{~L} / \mathrm{min}$; 45,000 fish/raceway; 2 raceways/treatment). The conventional hatchery environment consisted of barren concrete raceways, and fish were scatter-fed by hand. In contrast, enriched raceways (Natural Rearing Enhancement System-NATURES) were outfitted with camouflage-painted walls, underwater (denuded trees) and floating structures (camouflage netting attached to floating hoops), and sub-surface feeders (Fig. 1). In all hatchery treatments, fish were fed BioDiet grower pellets (BioOregon, Warrenton, OR, USA) at similar rations (Larsen et al., 2004). Water temperature at the hatchery ranged from $1{ }^{\circ} \mathrm{C}$ in January to $15{ }^{\circ} \mathrm{C}$ in late August. Fish were reared in this facility until volitional release (mid-March through May 2001).

\subsection{Tissue collection and analysis}

All fish were collected on April 25, 2001. All fish $(N=20$; five per group) were from the same genetic stock, and were collected at the same age. Migrating wild and conventional hatchery-reared smolts were collected at the Roza Dam by-pass facility. Fish from both conventional and enriched hatchery treatment groups were collected at Cle Elum Hatchery. Fish were euthanized $(0.05 \%$ tricaine methanesulfonate), and body weights and lengths were recorded. After decapitation, we exposed the brain, removed the lower jaw, and prefixed the head in Bouin's fixative $(6 \mathrm{hrs})$. Brains were then dissected, fixed again in Bouin's (12 hrs), and embedded in paraffin. Transverse sections $(5 \mu \mathrm{m})$ of the whole brain were mounted, and stained with luxol fast blue and cresyl violet.

Cross-sectional areas of the olfactory bulb (OB) and the telencephalon (TE) were measured serially in every 8th section (at $40 \mu \mathrm{m}$ intervals) and analyzed using Zeiss AxioVision Software. Volumes were calculated by summing the product of the cross sectional area for each section and the distance between sections (basic estimator of morphometric volume, Rosen and Harry, 1990). The OB was rostrally delineated from the olfactory nerve by the appearance of the OB external cellular layer and caudally by the disappearance of the glomerular layer. The caudal delineation of the TE, which included the entopeduncular nucleus but not the preoptic area, was the disappearance of the area dorsalis telencephali (Davis and Northcutt, 1983).

\subsection{Data analysis}

We made the following comparisons: First, we compared wild-reared individuals to fish reared in a conventional hatchery environment, Second, we compared fish reared in enriched environments to those reared in the conventional hatchery environment. We used $t$ tests to compare body size, the absolute volumes of forebrain structures, and the volumes of forebrain structures normalized both to body mass and to standard length. Here, we report both normalized values-rather than only brain volume/body mass which is more typically reported-because body mass in fish is dramatically influenced by immediate feeding status, which could not be controlled in migrating fish. All statistical tests were two-tailed and were performed using JMP 4.0.2 software (SAS Institute, Inc.).

\section{Results}

\subsection{Comparison 1: wild vs. conventional hatchery}

We found significant differences in the size of both the olfactory bulb and telencephalon between body-length sizematched fish (Fig. 2). The relative and absolute OB volumes of

Table 1

The effects of rearing environment on body size

\begin{tabular}{|c|c|c|}
\hline Treatment & $\begin{array}{l}\text { Standard length }(\mathrm{mm}) \text { range } \\
(\text { mean } \pm \text { SE })\end{array}$ & $\begin{array}{l}\text { Body mass }(\mathrm{g}) \text { range } \\
(\mathrm{mean} \pm \mathrm{SE})\end{array}$ \\
\hline Wild migrants & $117-127(120.8 \pm 1.7)$ & $14.2-19.7(16.6 \pm 1.0)$ \\
\hline $\begin{array}{l}\text { Conventional } \\
\text { migrants }\end{array}$ & $114-139(127.4 \pm 4.4)$ & $18.1-26.3(24.16 \pm 1.8)$ \\
\hline$t$-test & $t_{(1,8)}=1.391, p=0.2016$ & $t_{(1,8)}=2.375, p=0.0449$ \\
\hline $\begin{array}{l}\text { Conventional } \\
\text { hatchery }\end{array}$ & $120-148(137.2 \pm 4.9)$ & $18.6-32.6(27.86 \pm 2.4)$ \\
\hline $\begin{array}{l}\text { NATURES } \\
\text { hatchery }\end{array}$ & $118-137(128.6 \pm 3.6)$ & $16.1-26.6(21.74 \pm 1.9)$ \\
\hline$t$-test & $t_{(1,8)}=1.425, p=0.1919$ & $t_{(1,8)}=1.887, p=0.0959$ \\
\hline
\end{tabular}


wild fish were approximately $23 \%$ larger than the OBs of fish reared in the conventional hatchery treatment (Fig. 2A, relative volume, body weight: $t_{(1,8)}=-4.149, p=0.0032$, standard length: $t_{(1,8)}=-4.576, p=0.0018$; absolute volume, $t_{(1,8)}=$ $-3.368, p=0.0098)$.

TE volume normalized to both body weight and standard length was also approximately $25 \%$ larger in wild than in hatchery-reared fish (Fig. 2B, body weight: $t_{(1,8)}=-3.434$, $p=0.0089$, standard length: $\left.t_{(1,8)}=-2.602, p=0.0315\right)$. Absolute TE volumes were not significantly different between treatments $\left(t_{(1,8)}=-2.038, p=0.0759\right)$. Fish reared in conventional hatchery conditions were heavier than wild smolts, but did not differ in standard length (Table 1).

\subsection{Comparison 2: conventional vs. enriched hatchery}

We found no significant differences in the relative volume of either forebrain structure between fish reared in conventional and enriched hatchery treatments. However, absolute OB volume was significantly larger in fish reared in the conventional hatchery treatment $\left(t_{(1,8)}=2.5851, p=0.0324\right)$. When OB volume was normalized to body weight, treatments did not differ (Fig. 3A, $t_{(1,8)}=-0.747, p=0.4767$ ). However, when OB volume was normalized to standard length the difference between conventional and enriched fish was nearly significant (Fig. 3A, $t_{(1,8)}=-2.262, p=0.0535$ ).

\section{A Olfactory Bulb}
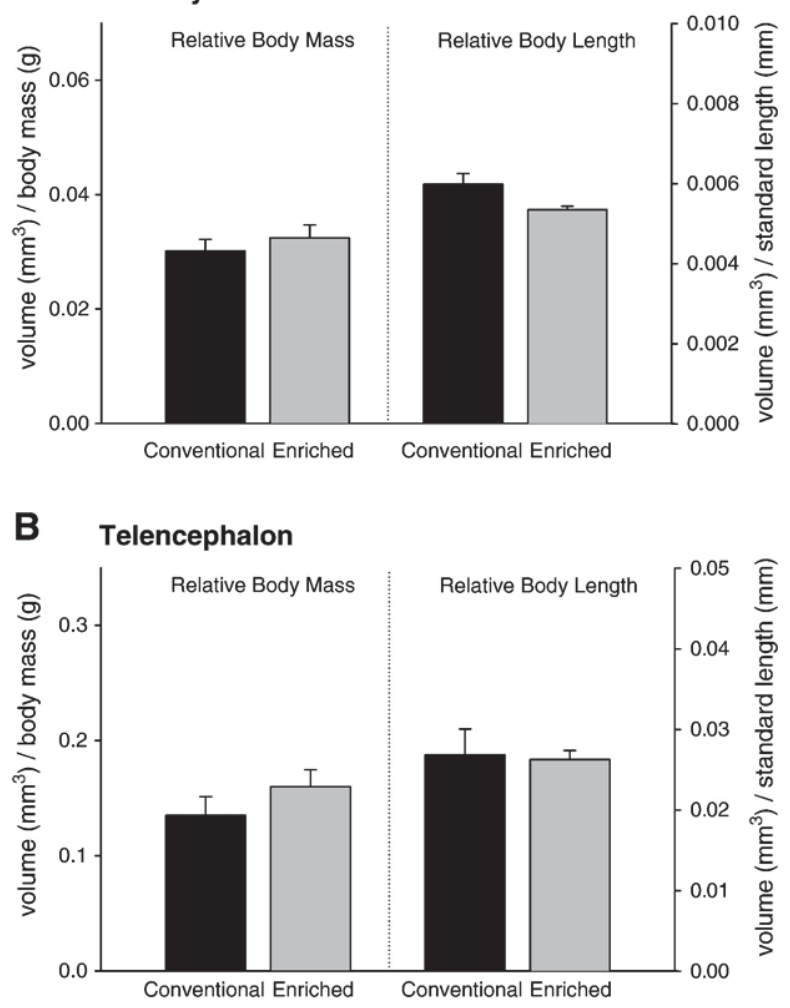

Fig. 3. Relative volume of the olfactory bulb (A) and telencephalon (B) shown normalized to body mass and standard length for juvenile salmon reared in conventional and NATURES enriched hatchery raceways. Values are plotted as mean \pm SEM.
Neither absolute nor relative TE volumes differed among hatchery rearing treatments (Fig. 3B, absolute: $t_{(1,8)}=0.675$, $p=0.5184$, relative to body weight: $t_{(1,8)}=-1.140, p=0.2872$, relative to standard length: $\left.t_{(1,8)}=-0.172, p=0.8677\right)$. We also observed no differences in body weight or length among wild and hatchery-reared smolts sampled at the Cle Elum Hatchery (Table 1).

\section{Discussion}

Here we show that the relative volumes of the olfactory bulb and telencephalon, and the absolute volume of the olfactory bulb, were larger in wild fish than in size-matched fish reared under conventional hatchery conditions. This study corroborates our previous report showing that hatchery-reared rainbow trout have smaller brains than wild fish, but uses a more robust volumetric measure that requires smaller sample sizes (Marchetti and Nevitt, 2003). Generally, it has been assumed that such significant differences in brain size could only result from artificial selection in captive rearing situations. For example, domesticated animals across a variety of taxa (e.g. turkeys, rabbits, pigs, sheep, llamas, ferrets, cats and dogs) typically have smaller relative brain sizes than their wild counterparts (Plogmann and Kruska, 1990; Ebinger and Rohrs, 1995; Kruska, 1996; for review see Kruska, 1988). Our study, however, suggests that at least in salmon, considerable differences in the size of two distinct forebrain structures can occur as a developmental consequence of rearing conditions.

\subsection{Factors contributing to brain differences}

We suggest three potential factors that could contribute to the differences in the size of forebrain structures we observed in this study. First, the developmental differences in brain growth could result from the impact of environmental stimuli on neural growth and proliferation. Effects of environmental stimuli on brain growth are well documented in other taxa. For example, in mammals, individuals exposed to enriched environments have increased levels of cell proliferation and dendritic arborization in the brain compared with animals only exposed to standard captive environments (Kempermann and Gage, 1999; van Praag et al., 2000; Faherty et al., 2003). In birds, the rate of experience-induced neurogenesis has been linked to changes in the volume of the hippocampus (Patel et al., 1997), suggesting that changes in neurogenesis can generate changes in brain size. In fish, social status and other environmental factors (e.g., temperature) are known to influence the size or number of neuroendocrine cells in the forebrain (Francis et al., 1993; Semsar and Godwin, 2003; Miranda et al., 2003; Lema, 2006), and may play additional roles in shaping neural phenotype. On the other hand, brain growth could be hindered by stressful conditions (e.g. crowding) in captivity. For example, in jewel fish, dendritic growth and arborization is depressed in fish reared under crowded conditions (Burgess and Coss, 1982). In other taxa, additional forms of developmental stress, including poor nutrition and maternal deprivation, are also known to reduce neural growth and the size of brain nuclei into adulthood (Buchanan et al., 2004; Mirescu et al., 2004). 
Environmental influences on circulating plasma thyroid hormone may also play a role in generating differences in the size of the olfactory bulb between hatchery and wild fish. This is because the thyroid-endocrine axis is sensitive to the environment that developing salmon experience (reviewed by Dittman and Quinn, 1996). In the hatchery, water quality, temperature and flow rate are typically more tightly controlled than in the wild, and all of these factors have been shown to stimulate thyroid hormone production (Dickhoff et al., 1982; Youngson and Simpson, 1984; Lin et al., 1985; Hoffnagle and Fivizzani, 1990). Thyroid hormone may, in turn induce neural or cellular proliferation. For example, we have recently shown that the active form of thyroid hormone, $\mathrm{T}_{3}$, induces cell proliferation in the peripheral olfactory system in Coho salmon parr (Lema and Nevitt, 2004b). It follows that thyroid hormone dependent cell proliferation may occur at different rates in hatchery and wild fish because these fish experience dramatically different environments. While we have not yet tested this idea directly, this hypothesis suggests at least one potential mechanism for how interacting with the wild environment might lead to a larger olfactory bulb (Nevitt and Dittman, 1998).

A second possibility is that the differences in relative brain size may stem from variation in somatic growth rate between fish reared in hatcheries and in the wild. Growth differences result because water temperature and food availability vary between rearing environments, and generate significant seasonal variations in somatic growth profiles (Larsen et al., 2004). For example, in Yakima River Spring Chinook salmon, wild fish grow faster in the summer and slower in the winter than their hatcheryreared counterparts (Larsen et al., 2004). It is not known, however, how variation in somatic growth rate is reflected in variation in neural growth rate. For example, it might be that brain growth, like somatic growth, is also temperature dependent, but not necessarily linked to body growth. However, these questions have yet to be studied.

Finally, the relationship between brain and somatic growth may vary developmentally (Pankhurst and Montgomery, 1994), which could confound comparisons of brain size between fish of different developmental or life-history stages. In this study, we measured brain growth during the process of smoltification, as the fish prepared for life in seawater. During smolting, fish experience dramatic physiological, morphological, and behavioral changes in a relatively short period of time. For instance, salmon generally experience a rapid drop in body condition factor (i.e., body mass relative to body length) during smolting. This change in body shape could bias comparisons of relative brain size for fish that are at different stages of smoltification (Pankhurst and Montgomery, 1994). Further, thyroid hormone levels increase during smolting (Dickhoff et al., 1978), and, as we previously mentioned, fluctuations in thyroid hormone levels are associated with cellular proliferation in the olfactory system (Nevitt et al., 1994; Lema and Nevitt, 2004b). Therefore, the size of the olfactory bulb may vary with smolt status, suggesting that such variation could have contributed to the differences we observed.

In this study, we did not make direct physiological measurements of smolt status for each fish. Instead, we classified fish as smolts by the behavioral measure of downstream migration. However, migrating fish may be at different stages of parr-smolt transformation, thus we were not able to verify that all fish were at the same developmental stage. To address the possible effects of changes in body shape during smolting, we compared OB and TE volume relative to standard length. When normalized to standard length (a measure that may not change as body condition factor drops during smolting) relative volumes of both structures were larger in migrating wild salmon than in migrating fish reared in the conventional hatchery treatment (Fig. 2). Further, we found no differences in the size of the forebrain structures between migrating and non-migrating fish from the conventional hatchery treatment, despite differences in smolt behavior. Still, the relative influence of developmental stage on the observed differences in brain growth between wild and hatchery-reared salmon is not known, and may be a fruitful area for future study.

\subsection{Timing of enrichment and potential links to behavior}

While other studies have shown that environmental enrichment influences brain size (e.g., mice: Rosenweig and Bennett, 1996), the size of the forebrain structures measured here did not differ between fish reared in the enriched treatment and in the conventional hatchery treatment. It is possible that this example of hatchery enrichment was inadequate to alter the volume of forebrain structures, but still induced other changes in neural architecture (e.g. neural proliferation, dendritic arborization) not examined in this study (Lema et al., 2005). It is also possible that environmental effects on brain size may be more substantial if fish are exposed to enrichment as soon as they hatch (Kihslinger and Nevitt, 2006). In this study, fish were transferred to their perspective rearing environments after they were several months old. However, the early rearing environment in hatcheries differs dramatically compared to the wild. In the wild, eggs are laid in gravel nests and hatch into alevins (yolk-sac fry). Alevins absorb their yolk sac over the next few weeks before emerging from the gravel into dynamic freshwater streams. By contrast, hatchery alevins are reared in highly dense tanks, with little environmental variability, enrichment, or natural substrate. Structural enrichment during the alevin lifestage has been shown to have positive impacts on the growth rate and behavior of salmon (Bams, 1967; Leon, 1975; Hansen and Møller, 1985). For example, fish reared with naturalistic substrate as alevins are larger as fry than those reared in standard hatchery tanks (Leon, 1975). Further, in related experiments, we have found that differences in the structural component of the alevin rearing environment can also influence the size of the cerebellum, suggesting that early enrichment may impact the trajectory of brain growth in salmon (Kihslinger and Nevitt, 2006).

In this study, we did not address how variation in the size of forebrain structures relates to the performance of fish after release into the wild. Although we found that wild rearing seems to produce juveniles with larger olfactory bulb and telencephalon volumes, hatchery and wild-reared fish from this system are known to return to spawn at similar rates as mature adults (Bosch 
et al., 2005). However, other behavioral experiments have been conducted using the 1999 cohort of Yakima River Spring Chinook salmon sampled from the same rearing environments as our study subjects. These preliminary results showed developmental differences in anti-predator behavior among fish reared in wild, conventional hatchery and enriched hatchery environments (Sampson and Fast, 2000). These authors found that wild-reared Yakima salmon were better at avoiding predators than fish reared in the conventional hatchery treatment. On the other hand, there was no difference between fish reared in conventional and enriched hatchery treatments, where we also found no difference in brain growth. Links between brain and behavioral differences that result from different rearing environments clearly need to be investigated further.

\subsection{Conclusions}

The results of our study suggest new avenues to explore with respect to environmental influences on brain growth. For example, understanding mechanistically how the environment influences brain development and subsequent behavior may lead to better conservation strategies in the future. For some threatened or endangered species, producing individuals in captivity that have a wild-type phenotype may be primary to their management and recovery (Baugh and Deacon, 1988; Brown and Day, 2002). Yet, our results suggest that designing captive propagation programs to produce fish that have wild neural and behavioral phenotypes may be more difficult than some people previously thought (see Snyder et al., 1996 and Wallace, 2000 for examples in other taxa). This type of neural analysis has not been applied before in conservation, but points to an innovative way to assess whether captive propagation is producing animals with wild phenotypes.

\section{Acknowledgements}

This work was funded by a UC Davis Faculty Research award to GAN. Additional funding was provided by the Northwest Fisheries Science Center Internal Grants Program, Washington State Hatchery Science Research Grant Program, and the National Science Foundation. We thank the staff of the Cle Elum Supplementation and Research Hatchery for providing the tissue used in this study, and for comments on previous manuscript versions. The authors also thank A. Alvarado, L. Chalupa, N. Hodges, P. Kareiva, R.T. Paine, I. Silverman and NMFS staff researchers for their assistance in the preparation of this manuscript. This paper constitutes part of RLK's PhD dissertation.

\section{References}

Bams, R.A., 1967. Differences in performance of naturally and artificially propagated Sockeye salmon migrant fry, as measured with swimming and predation tests. J. Fish. Res. Board Can. 24, 1117-1153.

Baugh, T.M., Deacon, J.E., 1988. Evaluation of the role of refugia in conservation efforts for the Devils Hole pupfish, Cyprinodon diabolis Wales. Zool. Biol. 7, 351-358.

Berejikian, B.A., Tezak, E.P., Flagg, T.A., LaRae, A.L., Kummerow, E., Mahnken, C.V.W., 2000. Social dominance, growth, and habitat use of age-0 steelhead (Oncorhynchus mykiss) grown in enriched and conventional hatchery rearing environments. Can. J. Fish. Aquat. Sci. 57, 628-636.

Bosch, B., Fast, D., Sampson, M. Yakima/Klickitat fisheries project monitoring and evaluation; Yakima Nation. 2004-2005 Annual Report, Project No. 199506325, 215 electronic pages (BPA Report DOE/BP-00017635-1).

Brandstatter, R., Kotrschal, K., 1990. Brain growth patterns in four European cyprinid fish species (Cyprinidae, Teleostei): roach (Rutilus rutilus), bream (Abramis brama), common carp (Cyprinus carpio) and saber carp (Pelecus cultratus). Brain Behav. Evol. 35, 195-211.

Brown, C., Day, R.L., 2002. The future of stock enhancements: lessons for hatchery practice from conservation biology. Fish Fish. 3, 79-94.

Buchanan, K.L., Leitner, S., Spencer, K.A., Goldsmith, A.R., Catchpole, C.K., 2004. Developmental stress selectively affects the song control nucleus HVC in the zebra finch. Proc. R. Soc. Lond., B biol. Sci. 271, 2381-2386.

Burgess, J.W., Coss, R.G., 1982. Effects of chronic crowding stress on midbrain development - changes in dendritic spine density and morphology in jewel fish optic tectum. Dev. Psychobiol. 15, 461-470.

Davis, R.E., Northcutt, R.G., 1983. Fish Neurobiology. The University of Michigan Press, Ann Arbor, MI.

Dickhoff, W.W., Folmar, L.C., Gorbman, A., 1978. Changes in plasma thyroxine during smoltification of Coho salmon, Oncorhynchus kisutch. Gen. Comp. Endocrinol. 36, 229-232.

Dickhoff, W.W., Darling, D.S., Gorbman, A., 1982. Thyroid function during smoltification of salmonid fish. Gunma Symp. Endocrinol. 19, 45-61.

Dittman, A., Quinn, T., 1996. Homing in Pacific salmon: mechanisms and ecological basis. J. Exp. Biol. 199, 83-91.

Ebinger, P., Rohrs, M., 1995. Volumetric-analysis of brain structures, especially of the visual-system in wild and domestic turkeys (Meleagris gallopavo). J. Brain Res. 36, 219-228.

Faherty, C., Kerley, D., Smeyne, R., 2003. A Golgi-Cox morphological analysis of netironal changes induced by environmental enrichment. Dev. Brain Res. $141,55-61$.

Flagg, T. A., Berejikian, B. A., Colt, J. E., Dickhoff, W. W., Harrell, L. W., Maynard, D. J., Nash, C., E., Strom, M. S., Iwamoto, R. N., Mahnken, C. V. W., 2000. Ecological and behavioral impacts of artificial production strategies on the abundance of wild salmon populations: A review of practices in the Pacific Northwest. NOAA Technical Memorandum NMFS-NWFSC-41, 92.

Francis, R.C., Soma, K., Fernald, R.D., 1993. Social regulation of the brainpituitary-gonadal axis. Proc. Natl. Acad. Sci. U. S. A. 90, 7794-7798.

Gross, M., 1998. One species with two biologies: Atlantic salmon (Salmo salar) in the wild and in aquaculture. Can. J. Fish. Aquat. Sci. 55 (Suppl. 1), 131-144.

Hansen, T.J., Møller, D., 1985. Yolk absorption, yolk sac constrictions, mortality and growth during 1st feeding of Atlantic salmon (Salmo salar) incubated on Astro-turf. Can. J. Fish. Aquat. Sci. 42, 1073-1078.

Healy, S., Guilford, T., 1990. Olfactory-bulb size and nocturnality in birds. Evolution 44, 339-346.

Hoffnagle, T.L., Fivizzani, A.J., 1990. Stimulation of plasma thyroxine levels by novel water chemistry during smoltification in Chinook salmon (Oncorhynchus tshawytscha). Can. J. Fish. Aquat. Sci. 47, 1513-1517.

Huber, R., Staaden, M.J.v., Kaufman, L.S., Liem, K.F., 1997. Microhabitat use, trophic patterns, and the evolution of brain structure in African cichlids. Brain Behav. Evol. 50, 167-182.

Kempermann, G., Gage, F.H., 1999. New nerve cells for the adult brain. Sci. Am. $280,48-53$

Kihslinger, R.L., Nevitt, G.A., 2006. Early rearing environment impacts cerebellar growth in juvenile salmon. J. Exp. Biol. 209, 504-509.

Kotrschal, K., Palzenberger, M., 1992. Neuroecology of cyprinids: comparative, quantitative histology reveals diverse brain patterns. Environ. Biol. Fishes 33, 135-152.

Kotrschal, K., Staaden, M.V., Huber, R., 1998. Fish brains: evolution and environmental relationships. Rev. Fish Biol. Fish. 8, 373-408.

Kruska, D., 1996. The effect of domestication on brain size and composition in the mink (Mustela vison). J. Zool. 239, 645-661.

Kruska, D., 1988. Mammalian domestication and its effect on brain structure and behavior. In: Jerison, H.J., Jerison, I. (Eds.), Intelligence and Evolutionary Biology, vol. G17. Springer-Verlag, Berlin, pp. 211-250.

Larsen, D.A., Beckman, B.R., Cooper, K.A., Barrett, D., Johnston, M., Swanson, P., Dickhoff, W.W., 2004. Assessment of high rates of precocious 
male maturation in a spring Chinook salmon supplementation hatchery program. T. Am. Fish. Soc. 133, 98-120.

Lema, S.C., 2006. Population divergence in plasticity of the AVT system and its association with aggressive behaviors in a death valley pupfish. Horm Behav. 50, 183-193.

Lema, S.C., Nevitt, G.A., 2004a. Variation in vasotocin immunoreactivity in the brain of recently isolated populations of a death valley pupfish, Cyprinodon nevadensis. Gen. Comp. Endocrinol. 135, 300-309.

Lema, S.C., Nevitt, G.A., 2004b. Evidence that thyroid hormone induces olfactory cellular proliferation in salmon during a sensitive period for imprinting. J. Exp. Biol. 207, 3317-3327.

Lema, S.C., Hodges, M.J., Marchetti, M.P., Nevitt, G.A., 2005. Proliferation zones in the salmon telencephalon and evidence for environmental influence on proliferation rate. Comp. Biochem. Physiol., A 141, 327-335.

Leon, K.A., 1975. Improved growth and survival of juvenile Atlantic salmon (Salmo salar) hatched in drums packed with a labyrinthine plastic substrate. Prog. Fish-Cult. 37, 158-163.

Lin, R.J., Rivas, R.J., Grau, E.G., Nishioka, R.S., Bern, H.A., 1985. Changes in plasma thyroxine following transfer of young Coho salmon (Oncorhynchus kisutch) from fresh-water to fresh-water. Aquaculture 45, 381-382.

Marchetti, M.P., Nevitt, G.A., 2003. Effects of hatchery rearing practices on brain structures of rainbow trout (Oncorhynchus mykiss). Environ. Biol. Fishes 66, 9-14.

Maynard, D.J., Riley, S., Berejikian, B.A., Flagg, T.A., 2003. Development of a Natural Rearing System to Improve Supplemental Fish Quality. BPA Report DOE/BP-00000548-1 Project No. 1991-0550, pp. 1-188.

Miranda, L., Strobl-Mazzulla, P., Strussmann, C., Parhar, I., Somoza, G., 2003. Gonadotropin-releasing hormone neuronal development during the sensitive period of temperature sex determination in the pejerrey fish, Odontesthes bonariensis. Gen. Comp. Endocrinol. 132, 444-453.

Mirescu, C., Peters, J.D., Gould, E., 2004. Early life experience alters response of adult neurogenesis to stress. Nat. Neurosci. 7, 841-846.

Nevitt, G.A., Dittman, A.H., 1998. A new model for olfactory imprinting in salmon. Integr. Biol. 1, 215-223.

Nevitt, G.A., Dittman, A.H., Quinn, T.P., Moody, W.J., 1994. Evidence for a peripheral olfactory memory in imprinted salmon. Proc. Natl. Acad. Sci. U.S.A. 91, 4288-4292.
Pankhurst, N.W., Montgomery, J.C., 1994. Uncoupling of visual and somatic growth in the rainbow trout Oncorhynchus mykiss. Brain Behav. Evol. 44 149-155.

Patel, S., Clayton, N., Krebs, J., 1997. Spatial learning induces neurogenesis in the avian brain. Behav. Brain Res. 89, 115-128.

Plogmann, D., Kruska, D., 1990. Volumetric comparison of auditory structures in the brains of European wild boars (Sus scorfa) and domestic pigs (Sus scorfa $\mathrm{f}$. dom.). Brain Behav. Evol. 35, 146-155.

Rosen, G.D., Harry, J.D., 1990. Brain volume estimation from serial section measurements: a comparison of methodologies. J. Neurosci. Methods 35, $115-124$

Rosenweig, M.R., Bennett, E.L., 1996. Psychology of plasticity: effects of training and experience on brain and behavior. Behav. Brain Res. 78, 57-65.

Sampson, M., Fast, D., 2000. Monitoring and Evaluation Project Number 95 063-25. The Confederated Tribes and Bands of the Yakama Nation, Yakima/ Klickitat Fisheries Project, Final Report 2000. In Report to the Bonneville Power Administration, vol. Contract No. 00000650, Project No. 199506325 , pp. 265.

Semsar, K., Godwin, J., 2003. Social influences on the arginine vasotocin system are independent of gonads in a sex-changing fish. J. Neurosci. 23, 4386-4393.

Snyder, N.F.R., Derrickson, S.R., Beissinger, S.R., Wiley, J.W., Smith, T.B., Toone, W.D., Miller, B., 1996. Limitations of captive breeding in endangered species recovery. Conserv. Biol. 10, 338-348.

van Praag, H., Kempermann, G., Gage, F.H., 2000. Neural consequences of environmental enrichment. Nat. Rev., Neurosci. 1, 191-198.

Wallace, M.P., 2000. Retaining natural behaviour in captivity for reintroduction. In: Gosling, L.M., Sutherland, W.J. (Eds.), Behaviour and Conservation. Cambridge University Press, Cambridge, pp. 300-31400.

Youngson A.F. \& Simpson, T.H., 1984. Changes in serum thyroxine levels during smolting in captive and wild Atlantic salmon, Salmo salar L. J. Fish Biol. 24, 29-39. 